\title{
Calculation of Kinetic Parameters of Thermal Decomposition of Forest Waste using the Monte Carlo Technique
}

\author{
Alok DHAUNDIYAL ${ }^{1 *}$, Laszlo TOTH ${ }^{2}$ \\ ${ }^{1,2}$ Institute of Process Engineering, Doctoral School of Mechanical Engineering, \\ Szent István University, Gödöllö 2100, Hungary
}

\begin{abstract}
This paper deals with the pyrolysis of forest waste in the presence of an inert atmosphere. Experiments are carried out at different heating rates $\left(5^{\circ} \mathrm{C}, 10{ }^{\circ} \mathrm{C}\right.$ and $\left.15^{\circ} \mathrm{C}\right)$ to determine derivative thermogravimetric behaviour of the material. Unlike the conventional scheme, the Monte Carlo technique is implemented to solve the distributed activation energy model (DAEM). DAEM is transformed into the inverse pyrolysis problem to determine the kinetic parameters of thermal degradation of forest waste. Activation energy, the preexponential factor and the distribution parameters are estimated by introducing the Monte Carlo Technique in the thermal conversion process.
\end{abstract}

Keywords - Biomass; distributed activation energy model; Monte Carlo technique; pyrolysis.

\section{INTRODUCTION}

Modelling scheme of biomass pyrolysis can be performed on the basis of single reaction and multi-reaction models. Comprehensive details of these models are reviewed in previous research [1]-[4]. The latest and up-to-date approach to describe biomass pyrolysis pivots around the distributed activation energy model [5]-[7]. The numerical solution of DAEM is used to estimate kinetic parameters. The DAEM is converted into an inverse problem, so that realistic results can be derived. As the trade-off relationship between material decomposition and mathematical model is fail to impart the robustness in the results, therefore the Monte Carlo scheme is adopted to make the solution more pragmatic. Some of the latest developments and the effect of various parameters on the single-reaction model are investigated by Brown [8]. Gune and Gune [9] reported the effect of miscellaneous parameters on the behaviour of first Order DAEM. Dhaundiyal et al. [10], [11] performed a comprehensive analysis of various density functions to predict the nature of thermal decomposition of biomass through DAEM.

In this study, kinetic parameters are determined by using the Monte Carlo scheme. The primary objective of this paper is to introduce a new method of solving in-exact integrals encountered while solving the solid-state kinetic models. It is assumed that the approximated solution forms an injective set. The Gaussian function is considered to be the initial distribution function. Only with the help of derivative thermogravimetric (DTG) analysis, the kinetic parameters of thermal degradation of forest waste is obtained.

* Corresponding author.

E-mail address: alok.dext@hotmail.com

(C)2020 Alok Dhaundiyal, Laszlo Toth.

This is an open access article licensed under the Creative Commons Attribution License (http://creativecommons.org/

licenses/by/4.0), in the manner agreed with Sciendo. 


\section{NON-ISOTHERMAL DAEM AND ITS NUMERICAL SOLUTION}

DAEM is one of the multi-reaction models. The postulations, restriction and derivation of the non-isothermal $n^{\text {th }}$ DAEM equations can be found in literature [12], [13]. Non-isothermal equations for the first order as well as $n^{\text {th }}$ DAEM are given below:

$$
\begin{gathered}
(1-\alpha)=\int_{0}^{\infty} \exp \left(-\int_{0}^{t} \frac{A}{\beta} \exp \left(\frac{-E}{R T}\right) \mathrm{d} t\right) f(E) \mathrm{d} E, \\
(1-\alpha)_{n \neq 1}=\int_{0}^{\infty}\left[1-(1-n)\left(\int_{0}^{t} \frac{A}{\beta} \exp \left(\frac{-E}{R T}\right) \mathrm{d} t\right)\right]^{\frac{1}{1-n}} f(E) \mathrm{d} E,
\end{gathered}
$$

where

E activation energy;

$\alpha \quad$ conversion of biomass;

A frequency factor;

$R \quad$ gas constant;

$t$ time;

$T$ temperature;

$N$ reaction order;

$f(E)$ density function of the activation energy of the volatile release. In this case, the function $f(E)$ represents density function of the Gaussian distribution.

The approximated solution of equations (1) and (2) can be done using the asymptotic technique. Therefore, the whole integral comprises two different kinds of density functions. The first term of DAEM is density function of temperature distribution, or temperature integral, whereas the density function of activation energy forms the second part of computational process. On the basis of these demarcations, the approximation is performed. The asymptotic form of the mean $\left(E_{\mathrm{s}}\right)$ and the step width $\left(E_{\mathrm{w}}\right)$ of the temperature integral $\exp \left(\int_{0}^{t} \frac{A}{\beta} \exp \left(\frac{-E}{R T}\right)\right)$ is derived for the linear ramp rate of temperature as mentioned in the study [13], thus, $E_{s}=R T Y(\tau)$ and $E_{w}=\frac{E_{s}}{1+Y(\tau)}$, applying the energy scaling and introducing the energy correction factor, we get

$$
y_{s}=\frac{E_{s}}{E_{0}} \text { and } y_{w}=\frac{E_{w}}{E_{0}} .
$$

Therefore, the approximated form of temperature integral is:

$$
\exp \left(\int_{0}^{t} \frac{A}{\beta} \exp \left(\frac{-E}{R T}\right)\right) \sim \exp \left(-\exp \left(\left(\frac{y_{s}-y}{y_{w}}\right)\right)\right)
$$

where

$E_{0}$

$Y(\tau)$

$\tau=A . t$

mean value of activation energy;

Lambert W function;

time-scale factor. 
Equations (1) and (2) are simplified by incorporating functional expressions of the temperature integral and the distribution of activation energies.

$$
(1-\alpha) \sim \int_{0}^{\infty} \exp \left(-\exp \left(-\exp \left(\left(\frac{y_{s}-y}{y_{w}}\right)\right)\right)\right) \exp \left(-\beta(y-1)^{2}\right) \mathrm{d} y
$$

Similarly, for $n^{\text {th }}$ order reactions apply the binomial expansion on the equation (2):

$$
(1-\alpha)_{n \neq 1} \sim \sqrt{\frac{\beta}{\pi}} \int_{0}^{\infty}\left(1-\exp \left(\frac{y_{s}-y}{y_{w}}\right)+\left(\frac{n}{2}\right) \exp \left(2\left(\frac{y_{s}-y}{y_{w}}\right)\right)+\ldots\right) \exp \left(-\beta(y-1)^{2}\right) \mathrm{d} y,
$$

where $\beta=\frac{E_{0}^{2}}{2 \sigma^{2}}$ is a constant and $\sigma$ is standard deviation of Gaussian distribution function.

Using the Laplace asymptotic scheme for the interior points of the integral ' $d y$ ' (Equation (5) and Equation (6)), we get a leading behaviour of the remaining mass fraction of the volatile $(1-\alpha)$ for the first and $n^{\text {th }}$ order reactions.

$$
\begin{gathered}
(1-\alpha) \sim \frac{\exp \left(-\beta\left(y_{e}-1\right)\left(y_{e}+2 y_{w}-1\right)\right)}{\sqrt{1+\left(\frac{y_{e}-1}{y_{w}}\right)}} \\
(1-\alpha)_{n \neq 1} \sim 1-\frac{1}{\sqrt{2 \beta}}\left[\exp \left(-\beta\left(y_{e, n}-1\right)\left(2 y_{s}-y_{e, n}-1\right)\right)+\frac{n}{2} \exp \left(-2 \beta\left(y_{e, n}-1\right)\left(y_{s}-y_{e, n}\right)\right)\right]
\end{gathered}
$$

Equations (7) and (8) are the desired expressions for the first and $n^{\text {th }}$ order reactions. The values of $y_{e}$, and $y_{e, n}$ and $y_{e, n}^{\prime}$ represent the points where the exponents of the exponential term in equations (5) and (6) attain maximum values, respectively.

$$
\begin{gathered}
y_{e}=1+y_{w} Y\left(\frac{1}{2 \beta y_{w}{ }^{2}} \exp \left(\frac{y_{s}-1}{y_{w}}\right)\right) \\
y_{e, n}=1-\frac{1}{2 \beta y_{w}} \\
y_{e, n}^{\prime}=2 y_{e, n}-1
\end{gathered}
$$

\section{Monte-Carlo SCHEME}

The Monte Carlo method is a computational technique used to obtain an unknown parameter. It is a fundamental tool to calculate and simulate a set of maps which are independent and identically distributed with the same distribution as the set of all maps [14]. Guo et al. [15] reported that the evolution of bonds in pyrolysis could be simulated by combining the Boltzmann-Monte-Carlo algorithm with the percolation theory. In pyrolysis problem of coal, the Monte Carlo algorithm delineates the bond formation by using coupling 
or collision of radical fragment [15]. The concept of Monte-Carlo analysis is to understand the uncertainty in the system through random sampling. Random number generator assigns a random value to each variable within the demarcated limit. Thus, it helps to develop a robust scheme to solve the inverse problem. Mainly, the performance of any given model is carried out by the deterministic value of parameters, but Monte Carlo is very effective for those models that have no analytical solutions. However, sometimes deterministic approach may not be able to delineate the actual process, therefore it is necessary to enhance the decision ability of the model and the gap between numerical approximations and analytical solutions can be abridged. In this study, the area of the DTG curve is calculated by using the MonteCarlo scheme. The MATLAB software is used to generate random particles of 17 to 20 million, so that the approximated area is nearly equal to the area bounded by the DTG plane. The area under the DTG curve is estimated by using binary logic matrices, which helps to determine the number of particles enclosed by the DTG curves, or the number of particles bombarded on the DTG plane. Programming for computing the area under the curve is performed on the MATLAB interface.

$$
\left|\left(\frac{1}{\left(m_{0}-m_{\mathrm{r}}\right)} \beta\right) \int_{m_{\mathrm{t}}}^{m_{\mathrm{r}}}\left(\frac{\mathrm{d} m}{\mathrm{~d} T}\right) \mathrm{d} T\right| \sim\left(\frac{p}{n}\right) \cdot A
$$

Here:

$p \quad$ inbound particles;

$n$ total number of particles bombarded on the DTG plane;

A area under the DTG plane;

$m_{0}, m_{\mathrm{t}}$ and $m_{\mathrm{r}}$ are the initial, instantaneous and residual mass of biomass respectively.

\section{Application of Biomass}

Thermal degradation of pine waste is conducted in the presence of inert gas (Nitrogen) by using the thermogravimetry technique. The volumetric flow rate of the gas is $200 \mathrm{~mL} / \mathrm{min}$. The crucible holder of Alumina $\left(\mathrm{Al}_{2} \mathrm{O}_{3}\right)$ is used to hold the sample inside the heating chamber. The thermocouple type ' $R$ ' is used to measure the temperature of the sample. The derivative thermogravimetric data is used to explore the kinetic parameters of thermal degradation of pine samples. The test is conducted at the heating rates of $5{ }^{\circ} \mathrm{C} / \mathrm{min}, 10{ }^{\circ} \mathrm{C} / \mathrm{min}$ and $15^{\circ} \mathrm{C} / \mathrm{min}$. The chemical composition of the pine samples is shown in Table 1 .

Table 1. Chemical Composition of Pine NeEdles with High Heating Value (H.H.V)

\begin{tabular}{lllllll}
\hline $\mathbf{C}, \boldsymbol{\%}$ & $\mathbf{H}, \boldsymbol{\%}$ & $\mathbf{N}, \boldsymbol{\%}$ & $\mathbf{O , ~ \%}$ & Ash content, \% & $\mathbf{S}, \boldsymbol{\%}$ & H.H.V, MJ/kg \\
54.28 & 6.55 & 0.61 & 35.50 & 2.92 & 0.11 & 20.65 \\
\hline
\end{tabular}

\section{RESUlts AND DisCuSSiON}

Mathematical computation of the kinetic model is performed by using the Monte Carlo simulation method. The given pyrolysis problem is converted into the inverse form assuming the non-surjective nature of the co-domain of kinetic parameters. The estimated range of variation of activation energy is distinguished by its integral limit. The Brownian movements of bombarded particles on the DTG plane at different heating rates are illustrated in Fig. 1, 
Fig. 2, and Fig. 3. The number of inbound particles $(p)$ is used to determine the area (Equation (12)) enclosed by DTG curves at the heating rates of $5{ }^{\circ} \mathrm{C}, 10^{\circ} \mathrm{C}$ and $15{ }^{\circ} \mathrm{C}$. The estimated areas under the DTG curve at different heating rates are shown in Table 2. It is assumed that the significant behaviour of total integrand (Equation (1) and (2)) is about the central value $\left(E_{\mathrm{s}}\right)$ of temperature integral, thus it reflects the activation energy required to initiate the thermal decomposition of the pine waste. The upper limits of activation energies are estimated to be $154.47 \mathrm{~kJ} / \mathrm{mol}, 144.62 \mathrm{~kJ} / \mathrm{mol}$ and $147.64 \mathrm{~kJ} / \mathrm{mol}$ at the heating rates of $5{ }^{\circ} \mathrm{C} / \mathrm{min}, 10{ }^{\circ} \mathrm{C} / \mathrm{min}$ and $15{ }^{\circ} \mathrm{C} / \mathrm{min}$ for first-order reactions, respectively, whereas the upper range of activation energies for $n^{\text {th }}$ order reactions lies in the domain of $66.20 \mathrm{~kJ} / \mathrm{mol}$ to $69.56 \mathrm{~kJ} / \mathrm{mol}$ (Table 3).

Frequency factors calculated using the proposed scheme lie in between $10^{4}$ and $10^{7} \mathrm{~min}^{-1}$. The activation energy distribution (on the basis of mean value) among the different stages of decomposition of pine needles is illustrated in Fig. 4. It is indicated that the energy required during the dehydration phase of pine needles vary from $25 \mathrm{~kJ} / \mathrm{mol}$ to $50 \mathrm{~kJ} / \mathrm{mol}$, whereas the activation energy rises steadily until the char formation. The activation energy increases by $40 \%$ till the end of $58 \%$ conversion of pine waste. The activation energies of sigmoidal reactions get changed due to the variation of the heat of reactions (exothermic to endothermic). Unlike the drift in the activation energy at the end of dehydration of the pine needle sample, it is marginally very low at the onset of the char formation stage. The activation energies of pine needles during char formation gets increased by $9 \%$. The results are compared with different model-free methods and multi-component devolatisation mechanisms, and it has been found that the derived solution provided the same solution with comprehensive details of the variation of activation energies caused by temperature integral, as well as the density function. The average variation of activation energy due to the density function varies from $66 \mathrm{~kJ} / \mathrm{mol}$ to $76 \mathrm{~kJ} / \mathrm{mol}$, whereas the approximated solution of temperature integral has a significant role in deciding the overall activation energy of the pine-needles, as both the functions are intertwined in the distributed activation energy model, therefore it is necessary to demarcate the individual merit of them.

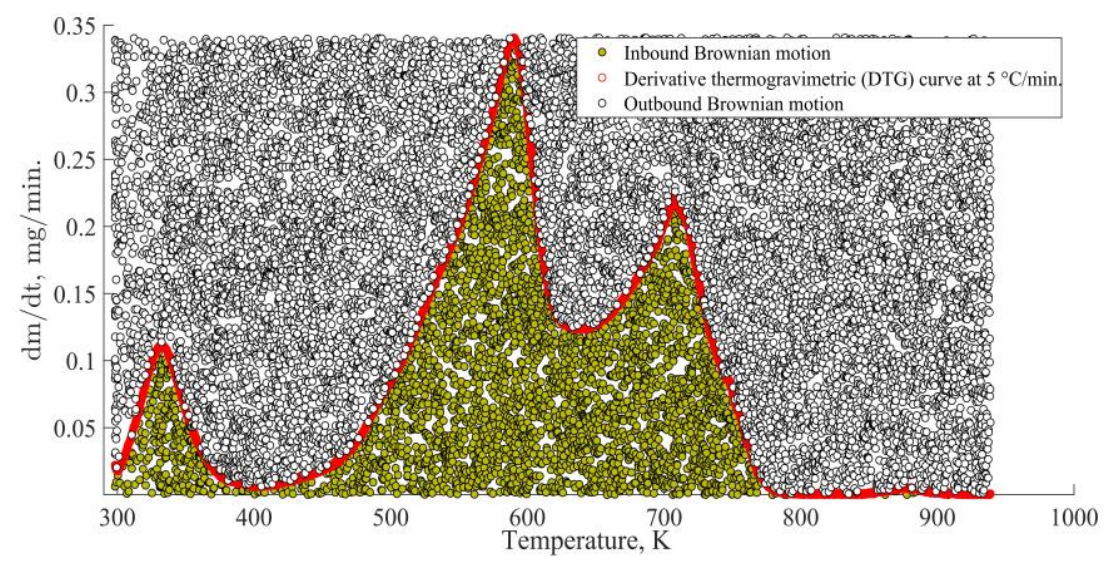

Fig. 1. Brownian motion of inbound and out bound particles on the DTG plane at $5{ }^{\circ} \mathrm{C} / \mathrm{min}$.

The significant contribution of the double exponential term to decide the shape and amplitude of the resultant curve is relatively high to the density function (the Gaussian distribution). Thus, the solution converges at the energy scaling factor ( $y$ ) from 1.3 to 1.4. 
The energy spacing of the temperature integral (or double exponential term), the kinetic parameters of $n^{\text {th }}$ order and the variance of the Gaussian energy distribution are estimated in Table 4.

It can be concluded that the proposed scheme has good agreement with other statistical methods, where the solution is predicted by the trade-off relationship between experimental and mathematical models. However, Monte Carlo simulation is also an approximated methodology, yet it reduces the scope of multiple iterations through the direct correlation of experimental data with a mathematical solution.

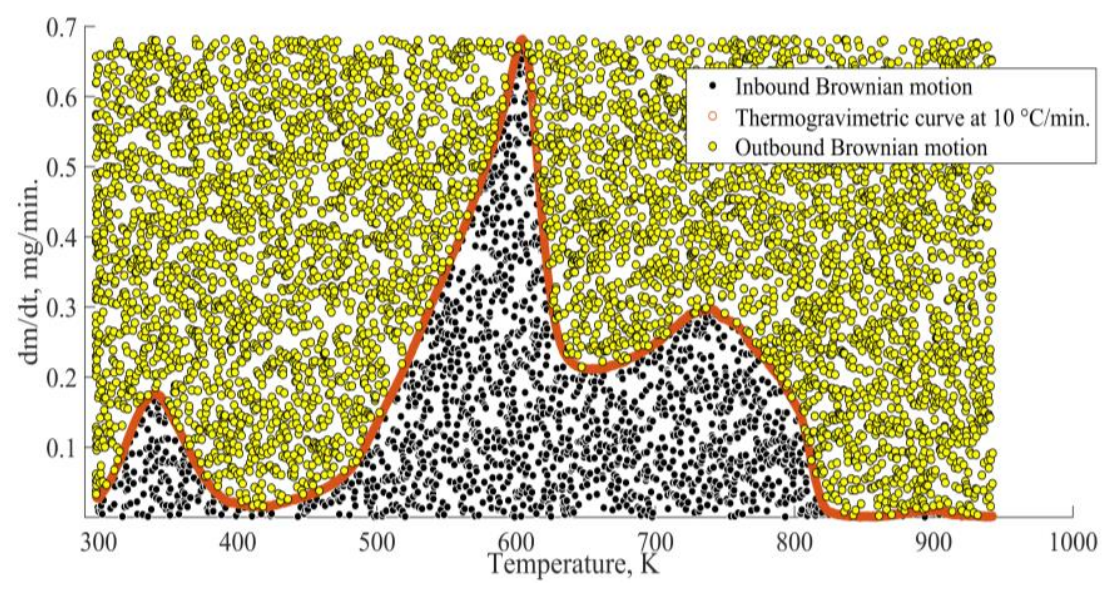

Fig. 2. Brownian motion of inbound and out bound particles on the DTG plane at $10^{\circ} \mathrm{C} / \mathrm{min}$.

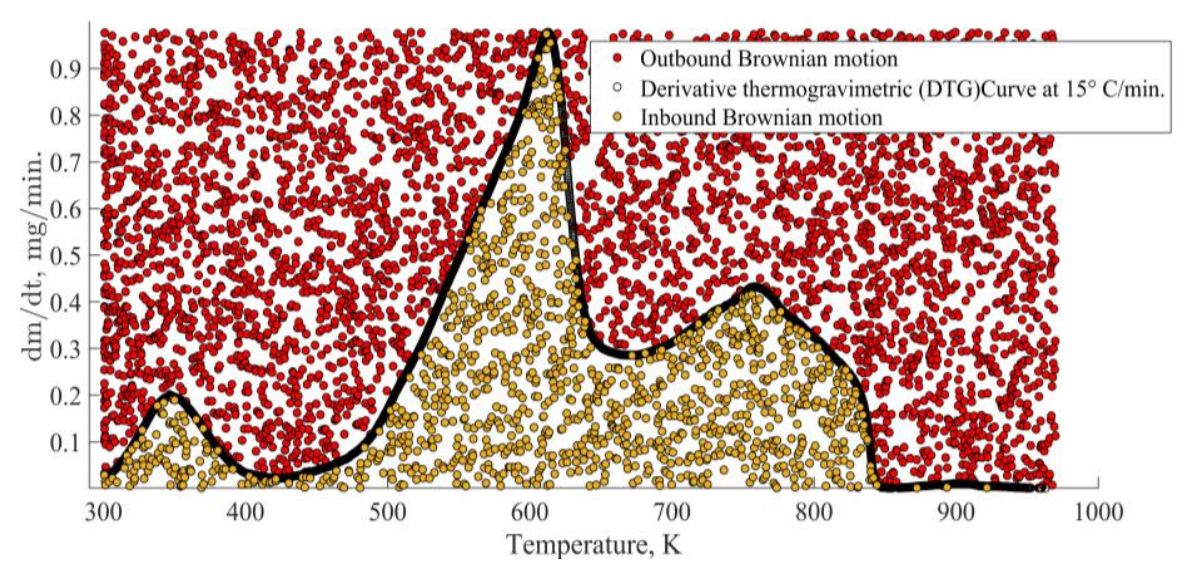

Fig. 3. Brownian motion of inbound and out bound particles on the DTG plane at $15^{\circ} \mathrm{C} / \mathrm{min}$. 


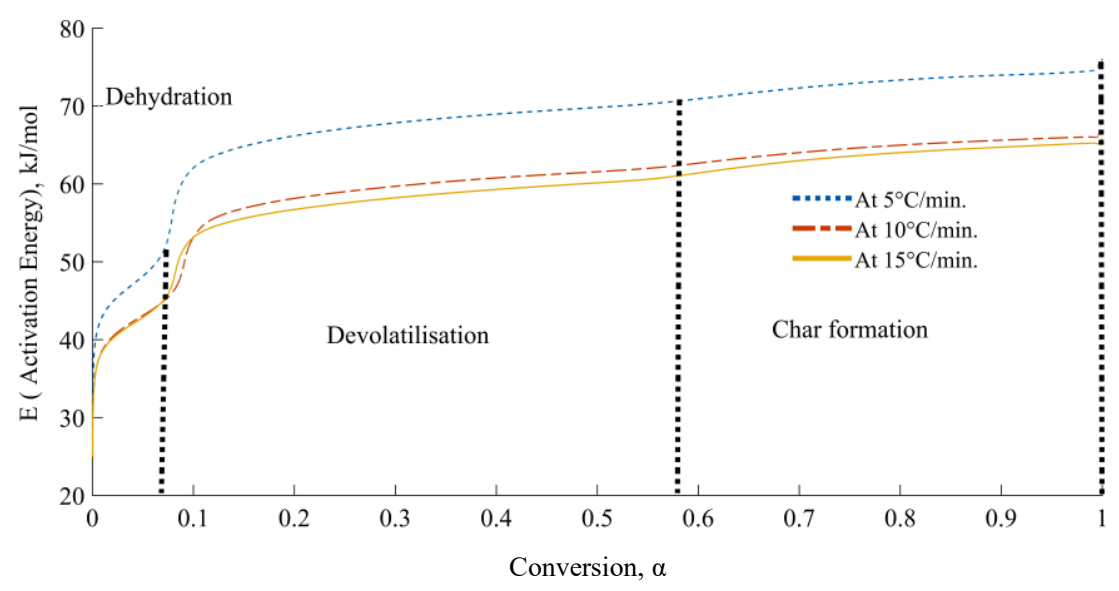

Fig. 4. Energy distribution at different stages of decomposition of pine needles.

Table 2. Calculated Area of the DTG Curves for Different Heating Rates

\begin{tabular}{lccc}
\hline $\begin{array}{l}\text { Heating rate } \\
\text { Area under curve (sq. Unit) }\end{array}$ & $5{ }^{\circ} \mathrm{C} / \mathrm{min}$ & $10{ }^{\circ} \mathrm{C} / \mathrm{min}$ & $15^{\circ} \mathrm{C} / \mathrm{min}$ \\
\hline$\left(\frac{1}{\left(m_{0}-m_{\mathrm{r}}\right)} \beta\right)^{m_{\mathrm{m}}} \int_{m_{\mathrm{t}}}\left(\frac{\mathrm{d} m}{\mathrm{~d} T}\right) \mathrm{d} T \mid=(1-\alpha)$ & 52.4866 & 104.3758 & 153.6810 \\
\hline
\end{tabular}

TABle 3. PARAMETRIC INFORMATION OF ThERMAL DECOMPOSITION OF Pine NEEDLES

\begin{tabular}{lllllll}
\hline \multirow{2}{*}{ Parameters } & \multicolumn{2}{l}{ First order reactions } & \multicolumn{3}{c}{$\boldsymbol{n}^{\text {th }}$ order reactions $(\boldsymbol{n}=\mathbf{0 . 0 0 2})$} \\
\cline { 2 - 7 } $\mathbf{5}^{\circ} \mathbf{C} / \mathbf{m i n}$ & $\mathbf{1 0}{ }^{\circ} \mathbf{C} / \mathbf{m i n}$ & $\mathbf{1 5}^{\circ} \mathbf{C} / \mathbf{m i n}$ & $\mathbf{5}^{\circ} \mathbf{C} / \mathbf{m i n}$ & $\mathbf{1 0}{ }^{\circ} \mathbf{C} / \mathbf{m i n}$ & $\mathbf{1 5}^{\circ} \mathbf{C} / \mathbf{m i n}$ \\
\hline$E_{0}, \mathrm{~kJ} / \mathrm{mol}$ & 76 & 66.72 & 65.94 & 20 & 27 & 26 \\
$A, \mathrm{~min}^{-1}$ & $6.39 \cdot 10^{7}$ & $3.10 \cdot 10^{7}$ & $3.96 \cdot 10^{4}$ & $5.44 \cdot 10^{2}$ & $6.56 \cdot 10^{2}$ & $7 \cdot 10^{2}$ \\
$\sigma^{2}, \mathrm{~kJ} / \mathrm{mol}$ & 89.3 & 75.49 & 81.76 & 2 & 2.0670 & 2.29 \\
$E_{\mathrm{s}}, \mathrm{kJ} / \mathrm{mol}$ & 99.50 & 92.08 & 92.78 & 43.022 & 40.55 & 38 \\
$E_{\mathrm{w}}, \mathrm{kJ} / \mathrm{mol}$ & 4.95 & 4.91 & 4.98 & 4.64 & 4.59 & 4.64 \\
\multirow{2}{*}{ Integral limit } & $26.79 \leq E_{\infty}$ & $25.15 \leq E_{\infty} \leq$ & $25.80 \leq E_{\infty} \leq$ & $3.15 \leq E_{\infty} \leq$ & $11.44 \leq E_{\infty} \leq$ & $3.53 \leq E_{\infty}$ \\
& $\leq 154.45$ & 144.62 & 147.64 & 69.56 & 66.38 & $\leq 66.20$ \\
\hline
\end{tabular}

TABLE 4. VAlidation of THE PRoposed SCHEME With the Other Methodologies

\begin{tabular}{|c|c|c|c|c|c|}
\hline \multirow{2}{*}{$\begin{array}{l}\text { Activation } \\
\text { Energy }\end{array}$} & \multirow{2}{*}{$\begin{array}{l}\text { Monte Carlo } \\
\text { Technique }\end{array}$} & \multicolumn{3}{|c|}{ Model- free methods [16] } & \multirow{2}{*}{$\begin{array}{l}\text { Multi-component } \\
\text { devolatilization } \\
\text { mechanism [17] }\end{array}$} \\
\hline & & FWO & KAS & Kissinger & \\
\hline$E, \mathrm{~kJ} / \mathrm{mol}$ & $92-100$ & 82.38 & 74.83 & 132.77 & $90-132$ \\
\hline
\end{tabular}

\section{Conclusion}

The kinetic parameters of thermal decomposition of pine needles have been derived using the Monte Carlo technique. The variation of activation energy is demarcated on the basis of temperature integral, as the significant contribution of temperature integral governs the 
integral problem of DAEM. The estimated value of activation energy varies between $92 \mathrm{~kJ} / \mathrm{mol}$ and $100 \mathrm{~kJ} / \mathrm{mol}$, whereas the lower limit of activation energy changes from $25 \mathrm{~kJ} / \mathrm{mol}$ to $26 \mathrm{~kJ} / \mathrm{mol}$. Similarly, the activation energy for the $n^{\text {th }}$ reactions varies from 38 to $43 \mathrm{~kJ} / \mathrm{mol}$ at the reaction order of 0.002 . The obtained values are within the permissible limit of variation as mentioned in literature [16]-[19]. The proposed scheme is relatively robust and precise to other methodologies. By applying the inverse function to calculate the kinetic parameters, the computational burden gets lessened. Secondly, it demarcates the activation energy variation caused by temperature integral from the energy distribution introduced by the density function of the distribution function. However, the nature of the inverse function for the proposed scheme must be non-surjective in its validation. It implies that the conversion at a particular time cannot have two different activation energies at the given heating rate. So, the solution must be non-trivial in nature. Apart from precise calculation of kinetic parameters, the mathematically formulated solution demands one to one mapping of variables, thus the solution must be injective, and the kinetic parameters must have a single value at the given conversion $(\alpha)$. Furthermore, should the bombarded particles cover the DTG plane completely, the technique would be more effective.

\section{ACKNOWLEDGEMENT}

This work was supported by the stipendium Hungaricum Programme and by the Institute of Process Engineering, Doctoral School of Mechanical Engineering, Szent Istvan University, Godollo, Hungary.

\section{REFERENCES}

[1] Capart R., Khezami L., Burnham A. K. Assessment of various kinetic models for the pyrolysis of a microgranular cellulose. Thermochimica Acta 2004:417:79-89. https://doi.org/10.1016/j.tca.2004.01.029

[2] Conesa J. A., Caballero J., Marcilla A., Font R. Analysis of different kinetic models in the dynamic pyrolysis of cellulose. Thermochimica Acta 1995:254:175-192. https://doi.org/10.1016/0040-6031(94)02102-T

[3] Dhaundiyal A., Singh S. B., Hanon M. M., Rawat R. Determination of Kinetic Parameters for the Thermal Decomposition of Parthenium hysterophorus. Environmental and Climate Technologies 2018:22(1):5-21. https://doi.org/10.1515/rtuect-2018-0001

[4] Yaroshenko A. P. Theoretical model and experimental study of pore growth during thermal expansion of graphite intercalation compounds. Journal of Thermal Analysis and Calorimetry 2005:79:515-519. https://doi.org/10.1007/s10973-005-0571-3

[5] Dhaundiyal A., Tewari P. Kinetic Parameters for the Thermal Decomposition of Forest Waste Using Distributed Activation Energy Model (DAEM). Environmental and Climate Technologies 2017:19(1):15-32. https://doi.org/10.1515/rtuect-2017-0002

[6] Dhaundiyal A., Singh S. B., Hanon M. M. Study of Distributed Activation Energy Model Using Bivariate Distribution Function, $\mathrm{f}\left(\mathrm{E}_{1}, \mathrm{E}_{2}\right)$. Thermal Science and Engineering Progress 2018:5:388-404. https://doi.org/10.1016/j.tsep.2018.01.009

[7] Galgano A., Blasi C. Di. Modeling Wood Degradation by the Unreacted-Core-Shrinking Approximation. Industrial \& Engineering Chemistry Research 2003:42:2101-2111. https://doi.org/10.1021/ie020939o

[8] Morgan D. J., Brown M. A. Introduction to Thermal Analysis: Techniques and Applications. London and New York: Chapman and Hall, 1988.

[9] Güneş M., Güneş S. The influences of various parameters on the numerical solution of non-isothermal DAEM equation. Thermochimica Acta 1999:336(1-2):93-96. https://doi.org/10.1016/S0040-6031(99)00207-5

[10] Dhaundiyal A., Singh S. B., Hanon M. M. Application of Archimedean copula in the non-isothermal $n^{\text {th }}$ order distributed activation energy model. Biofuels 2019:10:1-12. https://doi.org/10.1080/17597269.2018.1442662

[11] Dhaundiyal A., Singh S. B. Mathematical insight to non-isothermal pyrolysis of pine needles for different probability distribution functions. Biofuels 2018:9(5):647-658. https://doi.org/10.1080/17597269.2017.1329495

[12] Burnham A. K. Introduction to Chemical Kinetics. Global Chemical Kinetics of Fossil Fuels 2017:25-74. https://doi.org/10.1007/978-3-319-49634-4_2 
[13] Dhaundiyal A., Singh S. B. Distributed activation energy modelling for pyrolysis of forest waste using Gaussian distribution. Proceedings of the Latvian Academy of Sciences. Section B. Natural, Exact, and Applied Sciences 2016:70(2):64-70. https://doi.org/10.1515/prolas-2016-0011

[14] Cho W. K. T., Liu Y. Y. Sampling from complicated and unknown distributions: Monte Carlo and Markov Chain Monte Carlo methods for redistricting. Physica A: Statistical Mechanics and its Applications 2018:506:170-178. https://doi.org/10.1016/j.physa.2018.03.096

[15] Guo X., Liu Z., Xiao Y., Xu X., Xue X., Liu Q. The Boltzmann-Monte-Carlo-Percolation (BMCP) model on pyrolysis of coal: The volatiles' reactions. Fuel 2018:230:18-26. https://doi.org/10.1016/j.fuel.2018.05.016

[16] Dhaundiyal A., Abdulrahman T. M., Laszlo T. Thermo-kinetics of Forest Waste Using Model-Free Methods. Multidisciplinary Sciences 2019:24(1):465-495. https://doi.org/10.11144/javeriana.sc24-1.tofw

[17] Korobeinichev O. P., Paletsky A. A., Gonchikzhapov M. B., Shundrina I. K., Chen H., Liu. N. Combustion Chemistry and Decomposition Kinetics of Forest Fuels. Procedia Engineering 2013:62:182-193. https://doi.org/10.1016/j.proeng.2013.08.054

[18] Dhaundiyal, A., Toth, L. Modeling of Hardwood Pyrolysis Using the Convex Combination of the Mass Conversion Points. Journal of Energy Resources Technology, Transactions of the ASME 2019:142(6):061901. https://doi.org/10.1115/1.4045458

[19] Dhaundiyal, A. et al. Analysis of pyrolysis reactor for hardwood (Acacia) chips. Renewable Energy 2020:147(Part 1):1979-1989. https://doi.org/10.1016/j.renene.2019.09.095

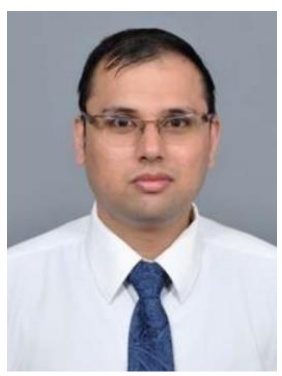

Alok Dhaundiyal had been awarded the master's degree in mechanical engineering from GBPUAT, Uttarakhand, India in 2014. From 2015 to 2017, he worked as an Assistant Professor in Himgiri Zee University. He has also worked on Deutsche Gesellschaft für Internationale Zusammenarbeit (GIZ) projects, which are the part of Indo-German Govt. Programme to promote renewable energy sector of India under the patronage of state government agency of Uttrakhand, India, UREDA; and Central ministry, Ministry of New Renewable Energy. The author's area of expertise is the energy generation through the biomass waste utilization.

In 2012, he has been awarded the Graduate Aptitude Test Engineering (GATE) Scholarship for Master of Engineering by the govt. of India. The Faculty of Engineering Excellence award has been conferred on him by the University of Strathclyde, Scotland, United Kingdom. He has also received University Grant Commission (2017 to 2022) scholarship. In 2017, the Stipendium Hungaricum Scholarship has been bestowed upon him by the government of Hungary. Currently, he has been pursuing his doctoral studies (Mechanical) at Szent István Egyetem (St. Stephen University), Hungary. ORCID iD: https://orcid.org/0000-0002-3390-0860

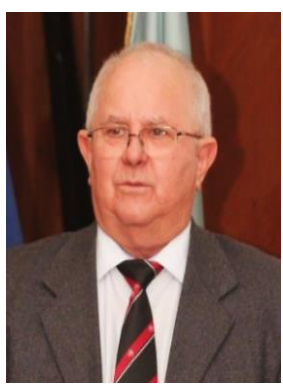

Prof. (Emeritus) Laszlo Toth (DSc.) had received his PhD Degree from University of Agricultural Sciences, Gödöllő in 1967. In 1986, he had been awarded the Doctor of Science by the Hungarian Academy of Science, Budapest, Hungary. He has been working as Professor in the Department of Energetics, Szent István University, Hungary, since 1995. He has research experience of 34 years and teaching experience of 20 years. Currently he is the Editor-in-chief of 'Journal of Agricultural Mechanisation', Hungary. He is also the President of the Hungarian Scientific Wind Energy Association, and a member of the World Wind Energy Association. $\mathrm{He}$ is also a member of the American Chemical Society and the American Society of Mechanical Engineers.

ORCID iD: https://orcid.org/0000-0003-0161-1375 